\title{
Análise do impacto dos projetos de interação entre a UFRGS e a PETROBRAS
}

\section{Impact analysis of interaction projects between UFRGS and PETROBRAS}

\author{
Ana Paula Matei ${ }^{1}$ \\ Carla Schwengber ten Caten ${ }^{1}$ \\ Ricardo Norberto Ayup Zouain ${ }^{1}$ \\ Ângelo Márcio Oliveira Sant'Anna²
}

\begin{abstract}
Resumo: Este trabalho tem o objetivo de analisar o impacto promovido por projetos de interação entre a UFRGS e a PETROBRAS, fomentados por fundos setoriais e incentivos governamentais. Com base em um levantamento e análise estatística multivariada, foram estudados projetos com foco em pesquisa e desenvolvimento (P\&D) das unidades acadêmicas da UFRGS. Foram analisados a inovação e os impactos associados à origem dos projetos, demanda da empresa, iniciativa do pesquisador e antecedentes de pesquisa usando análise estatística multivariada. A pesquisa não só explora aspectos implícitos e tácitos existentes no conhecimento acadêmico e científico, mas também propõe aspectos do conhecimento e da inovação que foram encontrados para contribuir na transferência de conhecimento. Palavras-chave: Gestão de projetos; Hélice tríplice; Transferência de conhecimento; Indústria de petróleo.
\end{abstract}

\begin{abstract}
This paper aims to analyze the impact promoted by interaction projects between UFRGS and PETROBRAS, fostered by sectorial funds and government incentives. Research and Development $(R \& D)$ projects from the academic units of UFRGS were investigated based on a survey and statistical multivariate analysis, assessing the innovation and impacts associated with the projects origin, company's demand, research's initiative and background. The research not only explores implicit and tacit aspects existing in the academic and scientific knowledge, but also proposes knowledge and innovation aspects that have been found to contribute to knowledge transfer.
\end{abstract}

Keywords: Project management; Triple helix; Knowledge transfer; Petroleum industry.

\section{Introdução}

A interação entre as instituições de ciência e tecnologia (ICT), mais especificamente as universidades, e o setor produtivo é uma questão estratégica relevante. Essa relação viabiliza um meio de aprimorar as atividades de pesquisa e desenvolvimento (P\&D) e, consequentemente, de aumentar a competitividade tecnológica das empresas e o avanço científico das instituições de pesquisa. Estes setores da economia, envolvidos no processo de inovação e desenvolvimento tecnológico nacional, apresentam-se de maneira complementar para o alcance de objetivos mutuamente benéficos e, ao mesmo tempo, distintos.

A academia, o governo e a indústria consideram a tecnologia como uma das principais fontes de competitividade, trazendo a inovação tecnológica como catalisador do desenvolvimento econômico, da melhoria da qualidade e da produtividade e, simultaneamente, melhoria dos padrões de vida sociais. Essas condições são fundamentais para que as empresas desenvolvam uma postura com foco tecnológico, a fim de definir as estratégias para aumentar o nível das tecnologias existentes, acessar e absorver as novas, principalmente visando às implicações da escassez de recursos e dos custos implícitos no desenvolvimento de inovações e técnicas necessárias para a sua competitividade (Vedovello, 1997; Vasconcelos \& Ferreira, 2000; Segatto-Mendes, 1996). Para determinados setores estratégicos, particularmente o de energia (petróleo e gás natural), as inovações tecnológicas tendem a ser mais complexas. Assim, a transferência de tecnologia é uma das formas mais intensas de realizar o intercâmbio de conhecimentos e habilidades tecnológicas entre as empresas e as ICTs (Coutinho, 2004).

\footnotetext{
${ }^{1}$ Universidade Federal do Rio Grande do Sul - UFRGS, Praça Argentina, s/n, Chateau, CEP 90040-020, Porto Alegre, RS, Brasil, e-mail: ana.matei@ufrgs.br; tencaten@producao.ufrgs.br; ricardo.ayup@ufrgs.br

${ }^{2}$ Universidade Federal da Bahia - UFBA, Rua Aristides Novis, 2, Federação, CEP 40210-630, Salvador, BA, Brasil, e-mail: angelo.santanna@ufba.br
} 
A PETROBRAS é notadamente uma empresa que permeia a fronteira tecnológica internacional no seu setor de atuação, assumindo uma característica singular quanto a sua liderança no avanço tecnológico em um país em desenvolvimento (Furtado, 1996). No entanto, a empresa está em constante desafio tecnológico para que possa assegurar o desenvolvimento e expansão das suas atividades em nível global. As recentes descobertas de novos reservatórios de petróleo, de grandes volumes, exigirão da empresa e do país uma resposta eficaz para a demanda tecnológica capaz de viabilizar e sustentar as estratégias para sua expansão (Zamith \& Santos, 1998; Coutinho, 2004).

O relacionamento entre as ICTs e a PETROBRAS foi consolidado anteriormente às mudanças legais ocorridas no contexto nacional (como a Lei do Petróleo e a Lei de Inovação Tecnológica). No entanto, a quebra do monopólio (incluindo a abertura do mercado e a participação de empresas como a Shell, Exxon, British Petroleum, entre outras) e a demanda por produtividade, somadas aos mecanismos que favorecem a interação com ICTs e outras empresas, fizeram com que esta empresa definisse uma nova política estratégica para gerir a inovação e a transferência de tecnologia necessária para o seu crescimento. Com este objetivo, a PETROBRAS definiu um sistema de redes temáticas de pesquisa vinculadas às políticas de investimento em $\mathrm{P} \& \mathrm{D}$.

Esta política considera a aplicação decorrente do Plano Nacional de Ciência e Tecnologia do Setor de Petróleo e Gás Natural - CTPETRO e da Participação Especial, estipulados pela Lei Federal no 9.478/97. Estas mudanças igualmente dinamizaram a política de desenvolvimento tecnológico a favor do setor e da economia nacional como um todo, permitindo o incremento de diversos segmentos estratégicos para a sociedade (Brasil, 1999b).

A produção de petróleo nacional e a consequente geração de riquezas só foram possíveis pela existência das atividades de pesquisa, desenvolvimento e engenharia de produtos e processos, envolvendo o trabalho de equipes de pesquisa que se dedicaram ao desenvolvimento científico e tecnológico aplicados ao setor petróleo e gás natural e dos investidores que acreditaram no potencial das ICT (PETROBRAS, 2015).

Contudo, é importante evidenciar os resultados desta interação, avaliando a capacidade de resposta do setor acadêmico às demandas da empresa, em níveis estratégicos e operacionais, otimizando esses benefícios a médio e longo prazo. A competência científica e de disseminação do conhecimento, que é uma das principais funções do setor acadêmico, também é objeto de avaliação, principalmente quando efetuada a partir da demanda do setor produtivo. Para a universidade, os resultados desta parceria são benéficos, colaborando para sua inserção social e econômica, gerando avanços científicos e tecnológicos e formando novos profissionais melhor qualificados para o mercado e a sociedade. Desta forma, objetivo principal é analisar o impacto promovido por projetos de interação entre a UFRGS e a PETROBRAS, fomentados por fundos setoriais e incentivos governamentais.

Na seção 2, é apresentado o referencial teórico sobre Interação entre Universidades, Empresas e Governo, o Contexto das Políticas de Ciência e Tecnologia no Brasil, o marco legal e os desafios tecnológicos do setor energético. A seção 3 apresenta os Procedimentos Metodológicos realizados para a elaboração deste trabalho e a seção 4, a Análise dos Resultados. A seção 5 apresenta as Conclusões da pesquisa realizada.

\section{Referencial teórico}

\subsection{Interação entre universidades, empresas e governo}

A inovação e o progresso tecnológico são resultados de um complexo conjunto de relações entre os atores produzindo, distribuindo e aplicando conhecimentos de variadas áreas. $O$ desempenho inovador de um país depende, em grande parte, da maneira como os agentes se relacionam entre si como elementos de um sistema coletivo de criação de conhecimentos e sua utilização, bem como da tecnologia utilizada. As interações podem assumir a forma de pesquisa conjunta, intercâmbio de pessoal, patentes em cotitularidade, aquisição de equipamentos e adequação de infraestrutura, dentre outras formas (OCDE, 2004).

Benedetti \& Torkomian (2011) realçavam o papel das universidades em um Sistema Nacional de Inovação, operando como fontes de conhecimentos científicos e de pesquisas que fornecem técnicas úteis para o desenvolvimento tecnológico industrial, além de atuarem como formadoras de cientistas e engenheiros. Todo o processo de inovação é complexo e depende de um codesenvolvimento de novas configurações sociotécnicas, novas estruturas de mercado, novos atores e novas instituições, além de depender de um contexto histórico e de condições espaciais e temporais para sua ocorrência (Markard \& Truffer, 2008).

Freeman (1987, p. 1) define os Sistemas de Inovação como uma "[...] rede de instituições nos setores público e privado, cujas atividades e iniciativas de interação, importam, modificam e difundem novas tecnologias." Os sistemas nacionais e regionais de inovação são mantidos sob o domínio da análise econômica, e sua importância advém das redes de interações que são fundamentais para que as empresas possam inovar. A influência do sistema nacional de educação, das relações industriais, das instituições técnicas e científicas, das políticas governamentais, das tradições culturais e de muitas outras instituições 
nacionais são fundamentais para estes sistemas e, consequentemente, para a inovação.

O Triângulo de Sábato e a Hélice Tríplice são definidos como o movimento coordenado para o avanço da relação de cooperação entre instituições científico-tecnológicas, empresas e governo, representados em modelos triádicos. O Triângulo de Sábato, proposto por Sábato e Botana em 1968, refere-se a um modelo para acessar e inserir a $C \& T$ no processo de desenvolvimento das nações, por meio da ação múltipla e coordenada de três elementos fundamentais: o governo, a estrutura produtiva e a infraestrutura científico-tecnológico (Rossi, 2010). A Hélice Tríplice de Relações Universidade-Indústria-Governo define o governo como agente principal na promoção da interação entre as indústrias e as universidades que, até o presente, tinham seus papéis institucionais separados e distintos e agora possuem, respectivamente, incentivos por um lado e a pressão de outro, de maneira a fomentar um desempenho superior nas atividades e funções tradicionais das universidades (Etzkowitz \& Leydesdorff, 1998).

A transferência de tecnologia é um processo de passagem de conhecimentos e de competências específicas (ex. resultados de pesquisas), que tem por finalidade promover a capacitação tecnológica das empresas receptoras (Lemos \& Joia, 2012) ou, ainda, um processo mútuo de intercâmbio de conhecimentos e habilidades tecnológicas entre ICTS e empresas (ANPROTEC, 2002). A Figura 1 apresenta alguns dos principais mecanismos de transferência de tecnologia que integram a prática de interação entre as universidades e as empresas.

Bozeman (2000) debate transferência de tecnologia e as diversas formas de interpretação e avaliação de eficiência na literatura, apresentando a progressão do

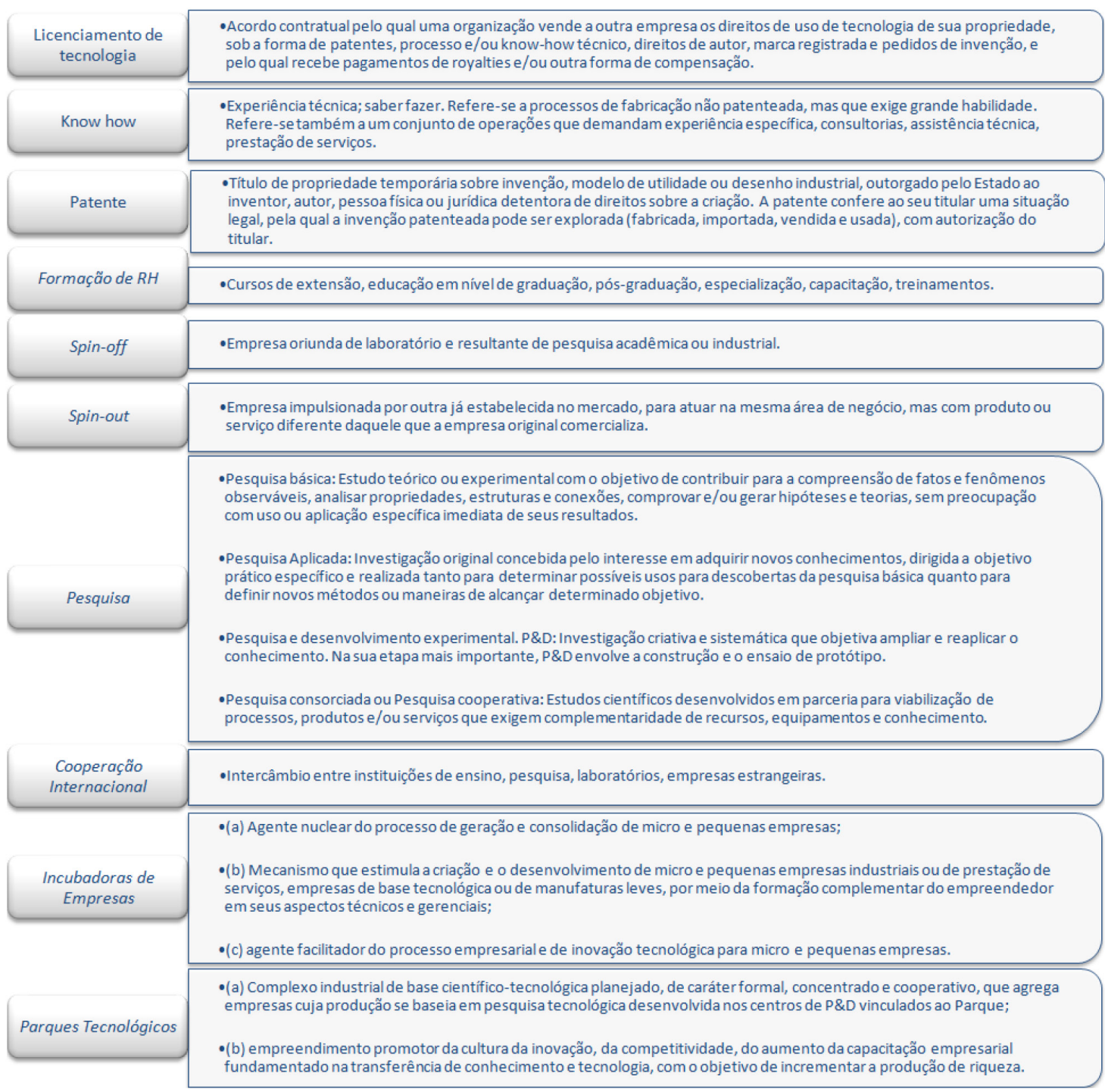

Figura 1. Mecanismos de Transferência de Tecnologia. Fonte: Adaptada de ANPROTEC (2002). 
conceito de transferência de tecnologia, de produto e uma visão mais ampla, englobando o conhecimento relacionado ao seu uso e aplicação. Ele descreve os elementos da transferência de tecnologia, os quais podem ser: agente de transferência, mecanismo de transferência, objeto de transferência, receptor da transferência e o ambiente demandante.

Para Feldman et al. (2002), as universidades têm experimentado e adotado mecanismos alternativos de transferência de propriedade intelectual. A ideia de participação das empresas como o pagamento pelo uso da propriedade intelectual da universidade são mecanismos emergentes. Acordos em que a universidade recebe a participação nos lucros de uma empresa em troca de prover à companhia a licença de uso dos direitos de invenção da universidade estão se tornando comum.

As operações de transferência de tecnologia têm múltiplos objetivos: aproxima vínculos entre universidade e indústria, aumenta o prestígio da universidade e aumenta e acelera a transferência de tecnologia para o benefício econômico e social da região ou nação. Toda a cooperação tecnológica é viabilizada pela colaboração entre empresas e instituições de ensino e pesquisa para o desenvolvimento de produtos e processos. Em geral, este tipo de cooperação reúne universidades e empresas para a formação de recursos humanos, acesso a laboratórios, apoio à pesquisa, ao desenvolvimento tecnológico e à transferência de tecnologia. Todo este ambiente está vinculado ao que chamamos de interação universidade-empresa, reunindo todas as atividades de transferência de tecnologia e conhecimentos entre a academia e o setor produtivo com vistas a promover inovação (OCDE, 2004; ANPROTEC, 2002).

Mowery \& Sampat (2005) apresentam estudos sobre a importância da pesquisa universitária para os avanços tecnológicos e a interação entre universidade e indústria. Os autores indicam alguns "produtos" importantes do ponto de vista econômico que resultam da pesquisa acadêmica, tais como: informações tecnológicas e científicas; equipamentos e instrumentação; capital humano; redes de capacidade científica e tecnológica; e o desenvolvimento de protótipos de novos produtos e processos.

\subsection{Contexto das políticas de ciência e tecnologia brasileiras}

O Brasil passa a contar com mecanismos governamentais de incentivo à pesquisa e desenvolvimento nas universidades a partir da década de 1950, com políticas de substituição de importações para bens de consumo duráveis e investimentos em infraestrutura, como na matriz energética e mineral. Ao longo desse período, foram criados a CAPES e o CNPq, em 1951. Quase duas décadas mais tarde, o governo criou o Fundo
Nacional de Desenvolvimento Científico e Tecnológico (FNDCT) administrado pela FINEP - Financiadora de Estudos e Projetos (criada em 1967). Este fundo setorial, até o presente momento, foi um dos principais mecanismos de incentivo ao desenvolvimento científico e tecnológico governamental, principalmente direcionado à interação entre o setor produtivo e as ICTs. Deste modo, o governo brasileiro estimula a modernização tecnológica brasileira, incentivando não apenas o $\mathrm{P} \& \mathrm{D}$ nas indústrias e universidades individualmente, mas principalmente em atuações conjuntas destas instituições (Vasconcelos \& Ferreira, 2000; Valle et al., 2002; CNI, 2008).

A partir de 1990, as políticas de ciência e tecnologia (C\&T) criadas para estimular a inovação integrada com empresas foram baseadas em mecanismos de incentivo fiscal para as atividades de $\mathrm{P} \& \mathrm{D}$ e capacitação tecnológica. Uma mudança importante nessa política foi a criação dos fundos setoriais em 1999, direcionados aos setores estratégicos nacionais. Estes fundos visavam a assegurar o fluxo de recursos destinados ao fomento da ciência, tecnologia e inovação, por meio das receitas advindas das empresas privatizadas naquele governo (Balestro, 2006).

O marco legal estabelecido com a aprovação da Lei do Petróleo (Lei no 9.478/1997) (Brasil, 1997) trouxe mudanças institucionais e elementos que colaboraram para dinamizar o setor de petróleo e gás natural, principalmente relacionado ao desenvolvimento tecnológico da economia brasileira. A principal mudança foi a de possibilitar o ingresso de empresas privadas do setor, nacionais ou estrangeiras, para atuarem no mesmo contexto produtivo, como consequência da quebra do monopólio da estatal sobre as atividades de exploração, produção, refino e transporte de petróleo, gás natural e coprodutos (ANP, 2005a). A Lei do Petróleo também dispõe sobre a distribuição de royalties a serem arrecadados à União em função da produção de petróleo e gás natural, dos quais $25 \%$ do excedente e $5 \%$ da produção deverão ser transferidos "[...] ao Ministério da Ciência e Tecnologia (MCT) para financiar programas de amparo à pesquisa científica $\mathrm{e}$ ao desenvolvimento tecnológico aplicados à indústria do petróleo [...]" (Brasil, 1999a, p. 2; Pereira, 2007).

A Lei trata, também, que o MCT administrará os programas com o apoio técnico da Agência Nacional do Petróleo - ANP, mediante convênios com as universidades e os centros de pesquisa do País (Brasil, 1999b). AAgência Nacional de Petróleo, Gás Natural e Biocombustíveis - ANP, fundamentada na referida lei, é o órgão regulador das atividades que integram a indústria do setor energético do petróleo, gás natural e biocombustíveis, sendo responsável pela execução da política nacional para o setor. Ela regula, contrata e fiscaliza as atividades das indústrias operadoras, exercendo ainda a função de promover o desenvolvimento dos setores regulados (ANP, 2014). 
Do mesmo modo, as concessionárias do setor têm previsto tanto em editais como em contratos que, além dos impostos usuais, as empresas devem pagar royalties aos Municípios, aos Estados e à União; e, no caso dos campos de grande volume de produção e rentabilidade, pagam também participações especiais. Esta participação especial, definida segundo a Lei no 9.478/97 e o Decreto no 2.705/98, “[...] será aplicada sobre a receita bruta da produção, deduzidos os royalties, os investimentos na exploração, os custos operacionais, a depreciação e os tributos previstos na legislação em vigor [...]" (Brasil, 1999a, parágrafo 1º, artigo 50). Portanto, os contratos de concessão passam a prever participações governamentais obrigatórias, e são definidas sob quatro aspectos, conforme apresenta o Quadro 1 (ANP, 2005b; Canciglieri et al., 2015).

A Resolução $n^{\circ} 33$ da ANP, de 2005, obriga os concessionários a investir, no Brasil, o valor correspondente a $1 \%$ da receita bruta da produção de um determinado campo na realização de despesas qualificadas como P\&D. Outra determinação da ANP obriga o concessionário a investir, no mínimo, $50 \%$ desse valor em despesas realizadas na contratação de projetos elou programas em universidades e institutos de $P \& D$, desde que previamente credenciados pela agência para este fim. Essas mudanças geraram um ambiente pertinente para a cooperação entre as universidades e as empresas do setor energético, principalmente no que confere ao $P \& D$ e às inovações tecnológicas, em virtude da experiência e qualificação demandadas (Brasil, 2005).

Verifica-se, portanto, que a partir do marco legal e das regulamentações técnicas geradas pela ANP no setor, em decorrência da Participação Especial e dos Fundos Setoriais, há possibilidades de explorar um amplo potencial científico e tecnológico alocado no País, gerando competências estratégicas para o setor energético, principalmente de petróleo e gás. Essa condição estabelece um marco referencial dinamizando as ações de pesquisa voltadas ao desafio de gerar novas tecnologias e inovações para os parceiros envolvidos. O desafio tecnológico que a indústria do petróleo possui está diretamente relacionado ao seu desenvolvimento e, principalmente, dos sistemas de produção que estão atrelados à adequada exploração e valorização dos reservatórios localizados em grande profundidade (Furtado, 1996). A mudança institucional ocorrida também se reflete em um grande desafio para os fornecedores nacionais, que tiveram de enfrentar um novo ambiente de concorrência (Closs \& Ferreira, 2012).

Com o Plano Nacional de Ciência e Tecnologia do Setor de Petróleo e Gás Natural - CTPETRO, realizado pelo Conselho Nacional de Política Energética - CNPE criado pela lei $n^{\circ} 9.478 / 97$ e decreto $n^{\circ} 2.851 / 98$, há um conjunto de programas de apoio à pesquisa científica e desenvolvimento tecnológico aplicados à indústria do petróleo. O objetivo principal do CTPETRO é contribuir para o desenvolvimento sustentável do setor. Dentre as principais estratégias, está a mobilização da comunidade de C\&T para atuação participativa, otimizando investimentos e compartilhando recursos; direcionando as atividades de $P \& D$ e de qualificação de recursos humanos; estimulando a apresentação de programas e projetos envolvendo cooperação entre centros de pesquisa, universidades e empresas que integram o circuito de interesses de produção final do produto ou processo, incentivando a constituição de redes cooperativas de pesquisa e inovação; entre outras (Brasil, 1999b, p. 3-5; Valle, et al., 2002).

Nas ações promovidas pelo CTPETRO, verifica-se a iniciativa de consolidação de um sistema setorial de inovação ao promover a articulação das instituições científicas e tecnológicas do País, envolvidas no processo de desenvolvimento tecnológico do setor petróleo e gás natural, integrando-se ainda mais com as empresas de bens de capital, empresas de petróleo e empresas de engenharia (Freitas, 2002).

A Lei Federal n 10.973 de 02/12/2004, conhecida como Lei de Inovação Tecnológica, também estabelece um marco histórico para fomentar a interação entre ICTs e empresas. Esta Lei dispõe sobre incentivos à inovação e à pesquisa científica e tecnológica no ambiente produtivo, a qual, além de instituir flexibilidades para a cooperação entre a universidade e as empresas, apresenta o apoio à criação de ambientes de inovação (Brasil, 2004).

Quadro 1. Obrigações contratuais das concessionárias.

\begin{tabular}{|l|l|}
\hline I - bônus de assinatura & $\begin{array}{l}\text { Valor mínimo estabelecido no edital e corresponderá ao pagamento ofertado na } \\
\text { proposta para obtenção da concessão, devendo ser pago no ato da assinatura do } \\
\text { contrato. }\end{array}$ \\
\hline II - royalties & $\begin{array}{l}\text { Pagos mensalmente, em moeda nacional, em montante correspondente a dez por } \\
\text { cento da produção de petróleo ou gás natural. }\end{array}$ \\
\hline III - participação especial & $\begin{array}{l}\text { A participação especial será aplicada sobre a receita bruta da produção, deduzidos } \\
\text { os royalties, os investimentos na exploração, os custos operacionais, a depreciação } \\
\text { e os tributos previstos na legislação em vigor. }\end{array}$ \\
\hline $\begin{array}{l}\text { IV - pagamento pela ocupação } \\
\text { ou retenção de área }\end{array}$ & $\begin{array}{l}\text { Pagamento pela ocupação ou retenção de área, a ser feito anualmente, fixado por } \\
\text { quilômetro quadrado ou fração da superfície do bloco. }\end{array}$ \\
\hline
\end{tabular}

Fonte: Adaptada de Lei n 9.478/1997 (Brasil, 1997). 
Com a nova configuração do ambiente legal e das políticas de C\&T, conforme o resumo das legislações pertinentes citadas neste artigo, as quais podem ser visualizadas no Quadro 2, a PETROBRAS estabeleceu algumas estratégias para estruturar sua política de inovação, desenvolvimento tecnológico e, principalmente, de interação com ICTs, em especial com as universidades, criando um modelo de parceria tecnológica. Este modelo foi proposto pelo CENPES e articulado com todas as áreas envolvidas com o Sistema Tecnológico da PETROBRAS. Com base neste modelo, foram propostos dois padrões estratégicos com as ICTs nacionais para definir as interações: os núcleos de competência e as redes temáticas.

Para tanto, a partir de 2006, foram apresentados o Sistema Tecnológico PETROBRAS e as Redes Temáticas para a execução das políticas estratégicas, com base no Regulamento Técnico $n^{\circ}$ 05/2005 da ANP (2005b), tornando o relacionamento de parceria tecnológica ainda mais intenso e adequando o ambiente favorável para fortalecer os interesses estratégicos da empresa, mas também de toda a comunidade científica e tecnológica nacional. O modelo de redes temáticas adotado pela PETROBRAS essencialmente apresenta os aspectos tecnológicos de interesse estratégico da empresa. Os projetos são desenvolvidos por redes colaborativas entre instituições de reconhecida competência nos temas selecionados, conforme o Quadro 3.

\section{Procedimentos metodológicos}

O procedimento metodológico contemplou uma abordagem qualitativa e quantitativa, estruturado nas seguintes etapas: 1) Coleta de Dados: (i) pesquisa bibliográfica; (ii) Levantamento (elaboração do instrumento de pesquisa, seleção das unidades de análise (amostra) e aplicação do instrumento de pesquisa); 2) Análise multivariada de dados - Tabelas Cruzadas (Crosstabs) e Análise de Correspondência (Correspondence Analysis - SPSS ${ }^{\circledR}$ ); e 3) Apresentação dos resultados.

\subsection{Coleta de dados}

\subsubsection{Pesquisa bibliográfica}

Foi realizado um levantamento bibliográfico dos principais artigos sobre interação universidade-empresa, desenvolvimento tecnológico e inovação, transferência de tecnologia e legislação para o setor energético, contemplando o histórico das instituições PETROBRAS e UFRGS.

\subsubsection{Levantamento}

Esta etapa consistiu na elaboração e na aplicação de um questionário fechado, com perguntas referentes à origem dos projetos e aos resultados obtidos pela execução destes, considerando os impactos científicos, tecnológicos e estratégicos tanto para a UFRGS como para a PETROBRAS. Foram realizadas entrevistas com coordenadores de projetos de interação entre a UFRGS e a PETROBRAS, os quais são docentes pesquisadores da universidade. Depois de contato por e-mail e telefone, informando sobre os objetivos da pesquisa, os entrevistados concordaram em participar, permitindo a gravação da entrevista.

As entrevistas foram orientadas por um questionário contendo 19 perguntas de múltipla escolha. Para cada resposta contemplada, foi atribuída uma nota referente ao grau de impacto, utilizando-se uma escala de 1 a 10 . A nota foi atribuída segundo a percepção dos docentes pesquisadores em relação aos resultados do projeto executado sob sua coordenação e o feedback dos gerentes da empresa PETROBRAS envolvidos nos projetos.

Os dados obtidos foram de origem primária (resultados dos questionários) e secundária (banco de dados sobre os contratos e convênios, disponibilizados pela Secretaria de Desenvolvimento Tecnológico da UFRGS). Para a definição da amostra, foram verificados o número de projetos totais por unidades acadêmicas e o objeto da interação destes projetos. Os 81 projetos analisados, entre os anos de 2004

Quadro 2. Resumo das legislações citadas.

\begin{tabular}{|c|c|}
\hline $\begin{array}{l}\text { Lei Federal no 9.478/1997 - Lei } \\
\text { do Petróleo (Brasil, 1997) }\end{array}$ & $\begin{array}{l}\text { Dispõe sobre a política energética nacional, as atividades relativas ao monopólio } \\
\text { do petróleo, institui o Conselho Nacional de Política Energética e a Agência } \\
\text { Nacional do Petróleo e dá outras providências. }\end{array}$ \\
\hline $\begin{array}{l}\text { Decreto Federal n }{ }^{\circ} 2.705 / 1998 \\
\text { (Brasil, 1998) }\end{array}$ & $\begin{array}{l}\text { Dispõe sobre programas de amparo à pesquisa científica e tecnológica aplicados } \\
\text { à indústria do petróleo, e dá outras providências. }\end{array}$ \\
\hline $\begin{array}{l}\text { Plano Nacional de Ciência e } \\
\text { Tecnologia do Setor de Petróleo } \\
\text { e Gás Natural - CTPETRO - } \\
\text { Portaria MCT n }{ }^{\circ} 552 \text { de 08/12/99 } \\
\text { (Brasil, 1999a) }\end{array}$ & $\begin{array}{l}\text { Tem como objetivo contribuir para o desenvolvimento do setor, por meio do apoio } \\
\text { financeiro a programas de amparo à pesquisa científica e ao desenvolvimento } \\
\text { tecnológico aplicados à indústria do petróleo e gás natural, visando ao aumento } \\
\text { da produção e da produtividade, à redução de custos e de preços, à melhoria da } \\
\text { qualidade dos produtos e da vida de todos quantos possam ser afetados por seus } \\
\text { resultados. }\end{array}$ \\
\hline $\begin{array}{l}\text { Lei Federal n } 10.973 / 2004 \text { de } \\
\text { Inovação (Brasil, 2004) }\end{array}$ & $\begin{array}{l}\text { Dispõe sobre incentivos à inovação e à pesquisa científica e tecnológica no } \\
\text { ambiente produtivo e dá outras providências. }\end{array}$ \\
\hline
\end{tabular}




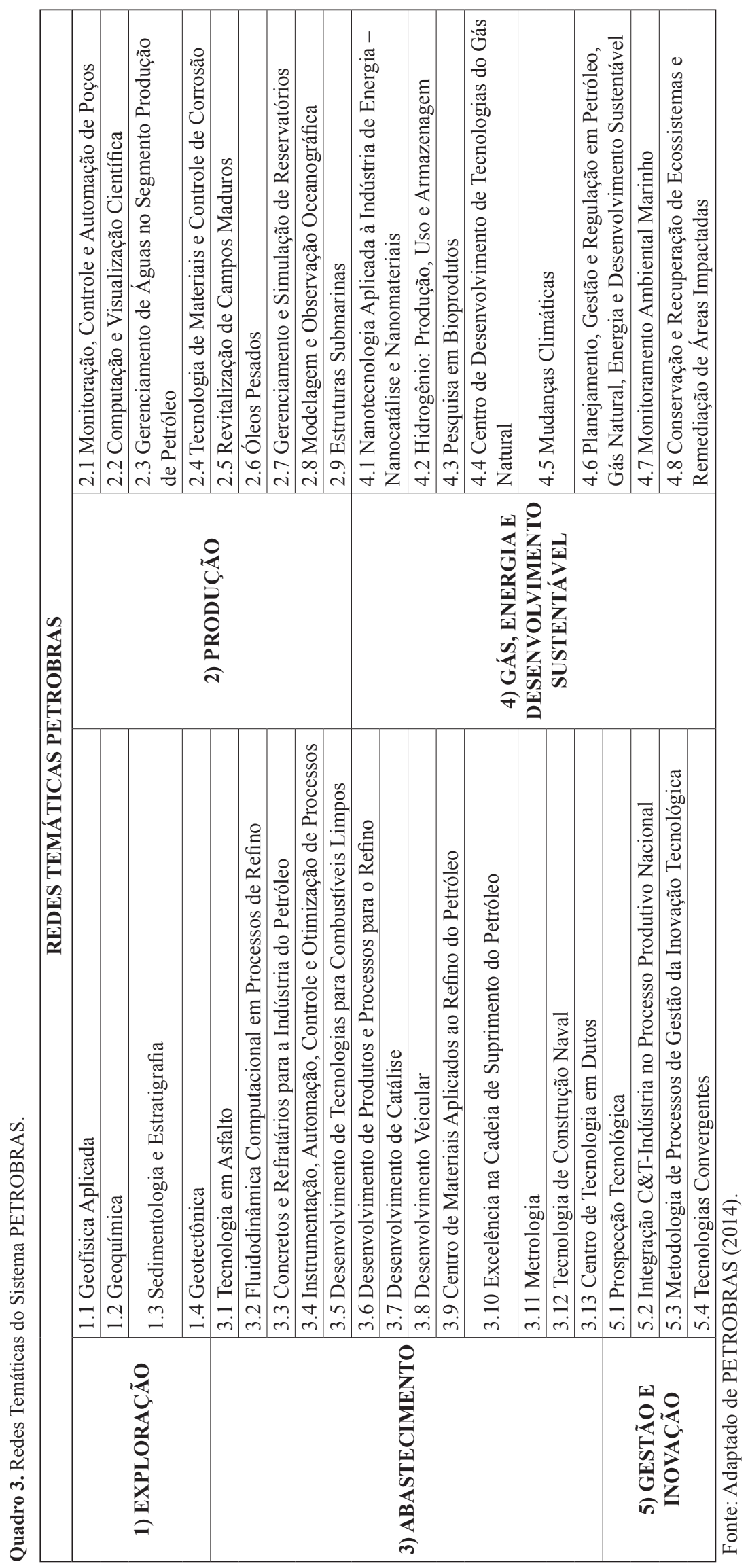


e 2008, considerando as unidades acadêmicas: 33 da Escola de Engenharia (EE), 24 do Instituto de Geociências (IG), e 12 do Instituto de Química (IQ), e os demais distribuídos entre outras unidades acadêmicas da UFRGS.

A título de definição em relação ao porte dos projetos, na UFRGS são considerados de pequeno porte aqueles até R\$ 250 mil (conforme a Portaria UFRGS n ${ }^{\circ}$ 2060/2006), de médio porte aqueles acima de R\$ 250 mil até R\$ 1 milhão, e de grande porte aqueles projetos acima de R\$ 1 milhão (UFRGS, 2006). O montante dos projetos totalizava mais de 90 milhões de reais

A definição da amostra foi por julgamento, selecionando as três unidades acadêmicas que apresentavam maior número de projetos de interação com a PETROBRAS. A seleção dos projetos considerou especificamente: $\mathrm{o}$ objeto da interação, o escopo do projeto executado e o foco em P\&D, sendo desconsiderados os projetos nos quais o objeto fosse apenas a instalação de infraestrutura física ou a prestação de serviços. Consideradas estas condições, foram selecionados 13 projetos de $\mathrm{P} \& \mathrm{D}$ das três maiores unidades acadêmicas, sendo 7 da EE, 3 do IG, 3 do IQ, dentre os quais, 6 eram de grande porte, 5 de médio porte e 2 de pequeno porte. Entrevistaram-se pessoalmente os coordenadores de cada projeto escolhido e os gerentes da empresa envolvidos nos projetos, sendo utilizado gravador de voz para auxiliar na coleta das informações.

\subsection{Análise multivariada de dados}

A análise dos dados foi realizada com a aplicação das Tabelas Cruzadas (Crosstabs) e da Análise de Correspondência (Correspondence Analysis) para uma variável de estratificação, definida com base na origem dos projetos, sendo, esta, referente à maneira pela qual foi identificada a oportunidade de realização do projeto. Esta estratificação foi definida como: (i) por demanda / encomenda da PETROBRAS; (ii) por iniciativa do pesquisador que identificou a parceria ou oportunidade de desenvolver o projeto para a PETROBRAS; e (iii) existiam antecedentes de pesquisa e verificou-se aplicação para a PETROBRAS.

A Análise de Correspondência é uma técnica de interdependência voltada para a redução dimensional e o mapeamento perceptual. É uma técnica composicional baseada na associação entre objetivos e um conjunto de características descritivas ou atributos especificados pelo pesquisador. O objetivo é determinar a frequência com que duas ou três variáveis aparecem juntas e retratar a correspondência das categorias de variáveis, medidas em escalas nominais, servindo de base para desenvolver mapas perceptuais (agrupamento de pontos). Esta técnica analítica então gera um mapa perceptual (de pontos espaciais), em que as categorias são representadas no espaço multidimensional, permitindo seu agrupamento cognitivo. A proximidade indica o nível da associação entre as categorias linha e coluna (Hair et al., 2005).

A análise de correspondência usa o conceito estatístico do teste quiquadrado das Tabelas de Contingência para padronizar os valores de frequência e formar a base para as associações. O teste quiquadrado foi utilizado para avaliar a associação entre as variáveis $\mathrm{X}$ e Y, considerando valores de resíduos ajustados maiores do que 1,96 (valor-p $<0,05$ ) que permitissem agrupar as categorias associadas (Sant'Anna, 2015). Esse nível de confiança foi definido devido ao tamanho da amostra ser pequeno. O cálculo dos valores referentes às informações obtidas nas questões foi corrigido pelos pesos respectivos atribuídos pelos coordenadores nas entrevistas. Este peso considerava o impacto de 1 a 10 nos resultados de cada questão apresentada. As análises foram realizadas como o auxílio do software SPSS-13 ${ }^{\circledR}$.

\section{Análise dos resultados}

Os resultados a seguir serão apresentados com base nas análises de correspondência. Contudo, é importante destacar algumas informações consideradas nas entrevistas. Dos 13 projetos pesquisados, 9 informaram que realizam interação com outras áreas de conhecimento (diferentes unidades acadêmicas da UFRGS). Os números totais de discentes envolvidos nos projetos por nível de escolaridade foram: 59 de graduação, 29 de mestrado e 27 de doutorado, além de 35 docentes doutores. No total, foram concedidas 74 bolsas de pesquisa envolvidas nos projetos. Com base nas médias simples, a duração dos projetos em anos é de 5,2 anos, e o tempo médio de relacionamento/ interação da UFRGS com a Petrobras é de 7,1 anos.

\section{1 Áreas de atuação da PETROBRAS}

Conforme as redes temáticas definidas pela empresa, conforme o Quadro 4, a distribuição das 15 diferentes áreas de atuação da PETROBRAS (2014), considerando o grau de impacto dos projetos em cada área de atuação. A Figura 2 apresenta a distribuição das áreas de atuação em função da origem dos projetos.

Os projetos demandados pela empresa estão mais associados com as áreas de Inovação em Combustíveis, Engenharia Básica, Fronteiras Exploratórias, Tecnologias Estratégicas de Refino, Modelagem de Bacias. Os projetos no qual o pesquisador identificou a oportunidade correspondem às áreas de Meio Ambiente, Produção em Águas Profundas, Transportes, Gás Natural, Energias Renováveis e Pré-sal. Finalmente, os oriundos de antecedentes de pesquisa com aplicação na empresa estão vinculados às áreas Recuperação Avançada do Petróleo, Otimização e Confiabilidade, Tecnologias Estratégicas de Refino e Mudanças Climáticas. 
Quadro 4. Tipos de Inovação.

\begin{tabular}{|l|l|}
\hline Em produtos tecnológicos & $\begin{array}{l}\text { Colocação no mercado de produtos novos ou aprimorados, resultantes do uso de } \\
\text { novo conhecimento, mudanças de equipamento e/ ou de organização da produção. }\end{array}$ \\
\hline Em processos tecnológicos & $\begin{array}{l}\text { Adoção de métodos de produção novos ou aprimorados, resultantes do uso de novo } \\
\text { conhecimento, mudanças de equipamentos e/ou de organização da produção. }\end{array}$ \\
\hline Em marketing & $\begin{array}{l}\text { Envolve a implementação de novos métodos de marketing, podendo incluir } \\
\text { mudanças na aparência do produto e sua embalagem, na divulgação e distribuição de } \\
\text { produto e em métodos para definir preços de benefícios e serviços. }\end{array}$ \\
\hline Organizacional & $\begin{array}{l}\text { Renovação de procedimentos e métodos de organizar empresas, fornecedores, } \\
\text { produção e comercialização de bens e serviços. }\end{array}$ \\
\hline Radical & $\begin{array}{l}\text { Introdução de novo produto ou processo ou renovação da forma de organização da } \\
\text { produção que pode resultar em ruptura estrutural com o padrão tecnológico até então } \\
\text { utilizado, dar origem a novas indústrias, setores ou mercados. }\end{array}$ \\
\hline Incremental & $\begin{array}{l}\text { Introdução em uma empresa, sem alteração da sua estrutura industrial, de qualquer } \\
\text { tipo de melhoria em produto, processo ou organização da produção. }\end{array}$ \\
\hline Tecnológica & Introdução de produtos e processos tecnologicamente novos ou aprimorados. \\
\hline
\end{tabular}

Fonte: Adaptado de ANPROTEC (2002) e Manual de Oslo (OCDE, 2004).

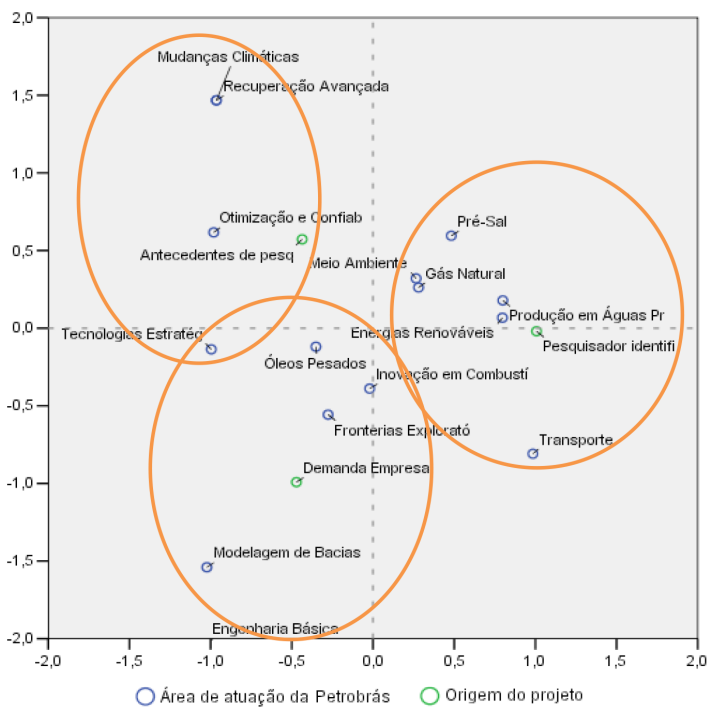

Figura 2. Áreas de Atuação da PETROBRAS em função da origem dos projetos.

\subsection{Objetivos científicos e tecnológicos dos projetos}

A identificação dos objetivos científicos e tecnológicos dos projetos foi considerada, visando relacionar os objetivos da inovação sugeridos pelo Manual de Oslo (OCDE, 2004). O Manual de Oslo foi elaborado para estruturar conceitos, definições e metodologias para auxiliar no entendimento dos processos de inovação. Nele é possível analisar diretrizes que possibilitam desenvolver indicadores de inovação e compará-los com a de países da OCDE (Organização para Cooperação e Desenvolvimento Econômico). Serve como um guia que estrutura e fornece parâmetros para a realização de pesquisas comparativas, além de auxiliar na compreensão sobre o tema da inovação para não especialistas. A Figura 3 apresenta os objetivos da inovação em função das origens dos projetos.

A Figura 4 ilustra que os objetivos científicos e tecnológicos associados à demanda da empresa são: desenvolver produtos amistosos ao meio ambiente, aumentar as linhas de produtos, abrir novos mercados e reduzir custos de exploração. Para aqueles em que o pesquisador identificou a oportunidade, enfatiza-se apenas aumentar a linha de produtos da empresa. No caso de antecedentes de pesquisa com aplicação na empresa, os objetivos científicos e tecnológicos mais associados são: gerar inovações em C\&T, aumentar a flexibilidade de produção, aumentar ou manter a participação de mercado e reduzir custos de produção.

\subsection{Tipo de inovações}

Os tipos de inovação também foram examinados, visando identificar de que maneira os resultados dos projetos impactariam inovações na empresa. De acordo com a ANPROTEC (2002) e Manual de Oslo (OCDE, 2004), os tipos de inovação podem ser classificados conforme o Quadro 4.

Para os projetos com origem na demanda da empresa destaca-se o tipo de inovação de produtos tecnológicos, radical e incremental. Nos projetos em que o pesquisador identificou a oportunidade, sobressaem-se as inovações de processos tecnológicos e, no caso de antecedentes de pesquisa com aplicação na empresa, as inovações são focadas em organizacional e tecnológica (ver Figura 5).

\subsection{Principais recursos demandados pela PETROBRAS para a realização do projeto}

A intenção de identificar os principais recursos ou quesitos demandados pela empresa para a realização dos projetos seria verificar os pontos fortes e fracos que 


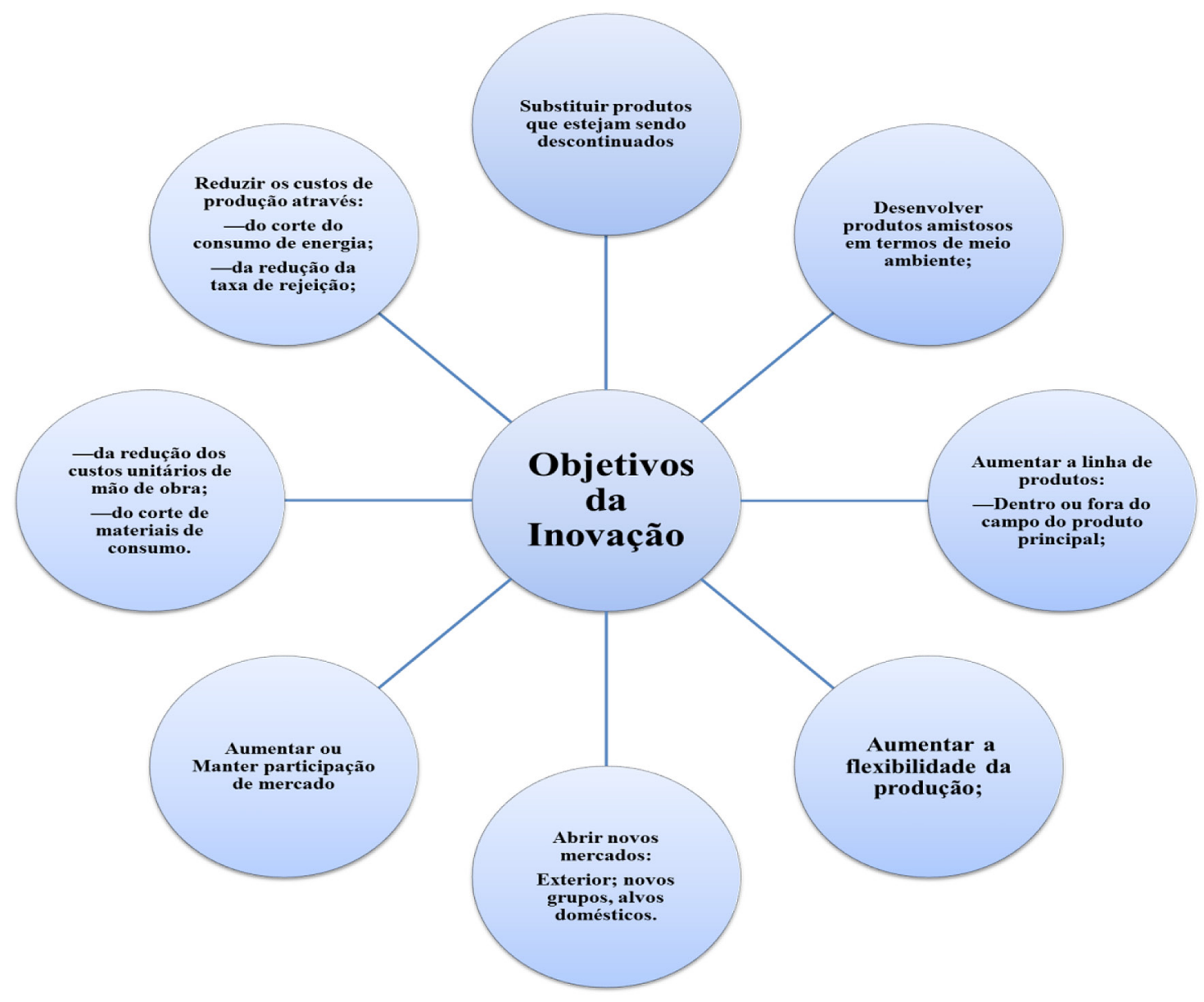

Figura 3. Objetivos da Inovação. Fonte: Adaptada de Manual de Oslo (OCDE, 2004).

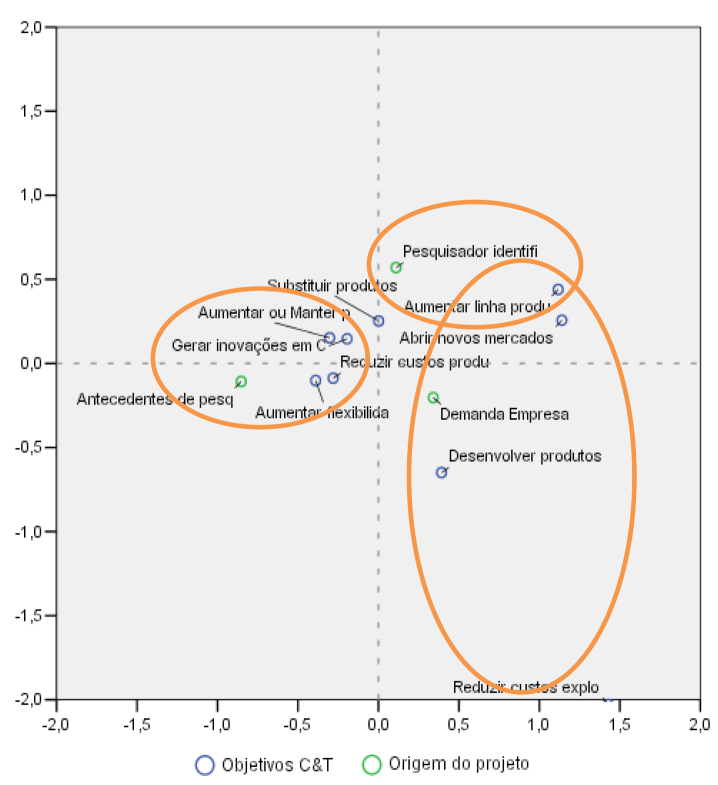

Figura 4. Objetivos de C\&T dos projetos em função da origem dos projetos. implicam para efetivar a interação. Para os projetos sob a demanda da empresa, destaca-se a necessidade de estrutura laboratorial e aporte de recursos financeiros adequados ao desenvolvimento dos projetos. Naqueles em que o pesquisador identificou a oportunidade são enfatizados a infraestrutura física e tecnológica e recursos humanos, enquanto que, os projetos oriundos de antecedentes de pesquisa relacionado às políticas de relacionamento definidas apresentam-se como o principal quesito exigido (ver Figura 6).

\subsection{Resultados passíveis de proteção}

A Figura 7 apresenta os resultados passíveis de proteção em função da origem dos projetos, que visavam identificar em que áreas ocorrem maior número de patentes, modelos de utilidade e softwares para a universidade e a empresa. Estes resultados também implicam negociações entre as instituições, considerando as políticas de propriedade intelectual de cada uma delas, especialmente da Universidade. É importante destacar que o relacionamento entre a 
Petrobras e as universidades brasileiras (ANDIFES) tem uma política específica para as tratativas em relação aos resultados protegíveis.

Conforme se visualiza, para projetos sob Demanda da empresa, são destacados Outros Resultados, enquanto que Modelos de Utilidade são recorrentes em projetos em que o Pesquisador identificou a oportunidade, e Patentes em projetos com Antecedentes de pesquisa com aplicação na empresa. Destaca-se que há pedidos de patente em análise pelo INPI em relação aos projetos desenvolvidos pela Escola de Engenharia e pelo Instituto de Química, oriundos destes projetos analisados.

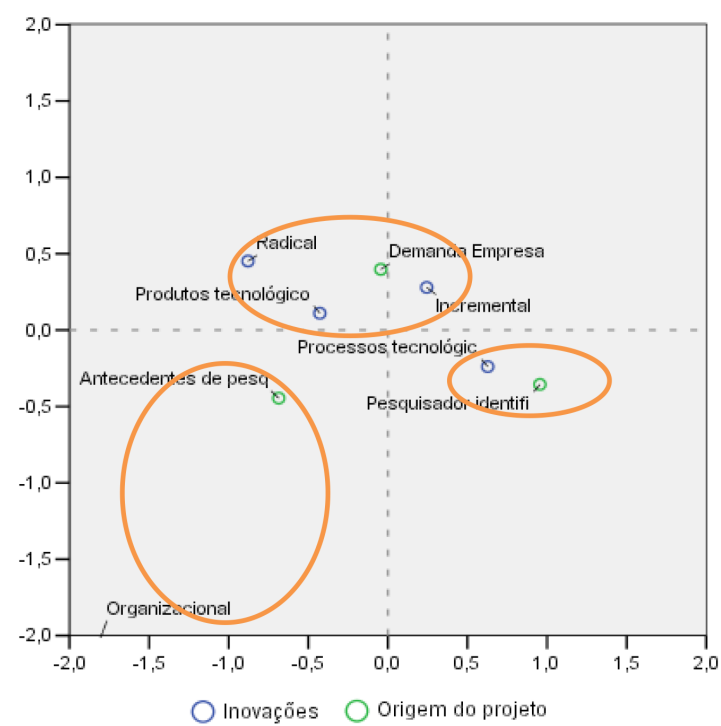

Figura 5. Principais tipos de inovação.

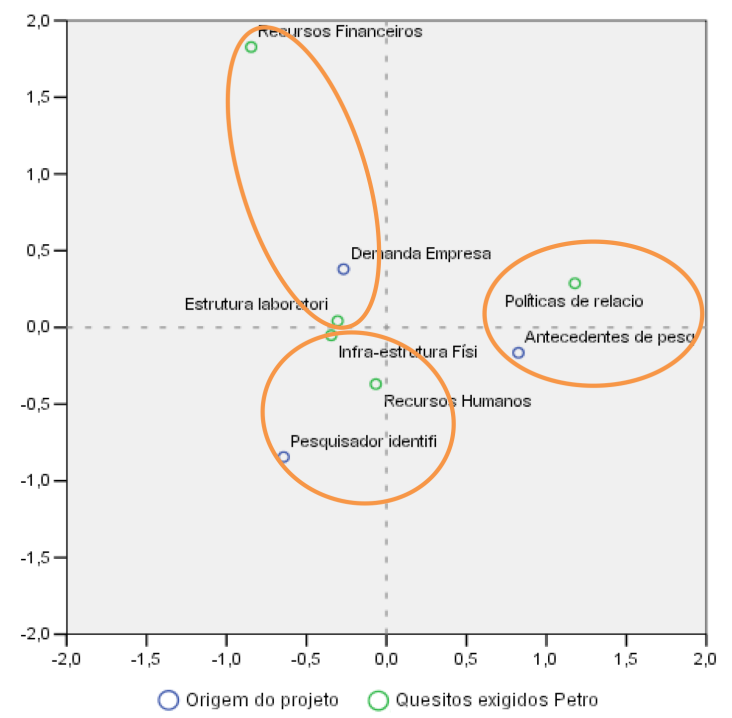

Figura 6. Recursos exigidos pela empresa para a realização dos projetos.

\subsection{Principais incentivos para a realização do projeto}

Esta questão visa identificar quais políticas de C\&T incentivaram a realização dos projetos. Os principais mecanismos de incentivo de interação Universidade-Empresa destinados ao setor de petróleo e gás natural são: Lei de Inovação Tecnológica, Fundos Setoriais (CTPETRO), Participação Especial (Lei do Petróleo), Conselho Nacional de Política Energética (CNPE) e Formação das Redes Temáticas do Sistema PETROBRAS de Tecnologia.

A Figura 8 apresenta os principais incentivos para a realização dos projetos em função da origem

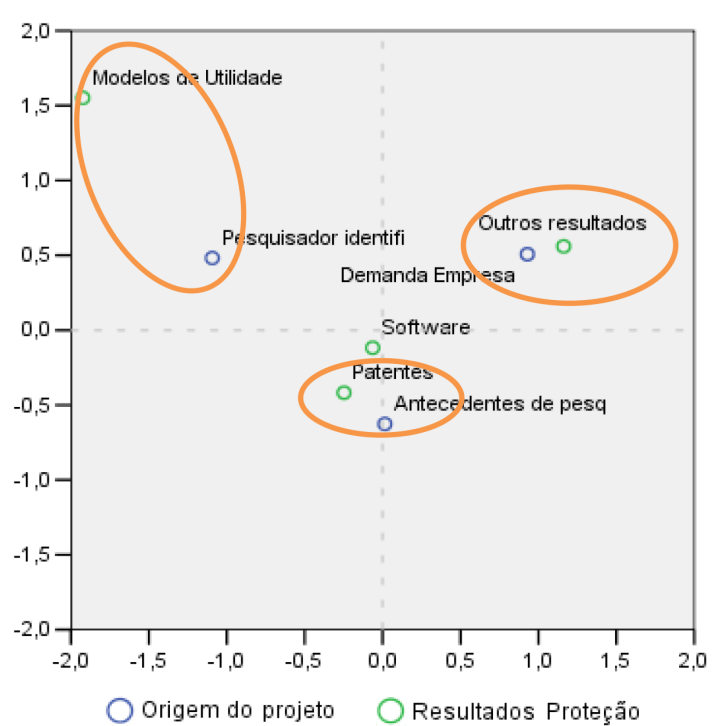

Figura 7. Principais resultados protegíveis.

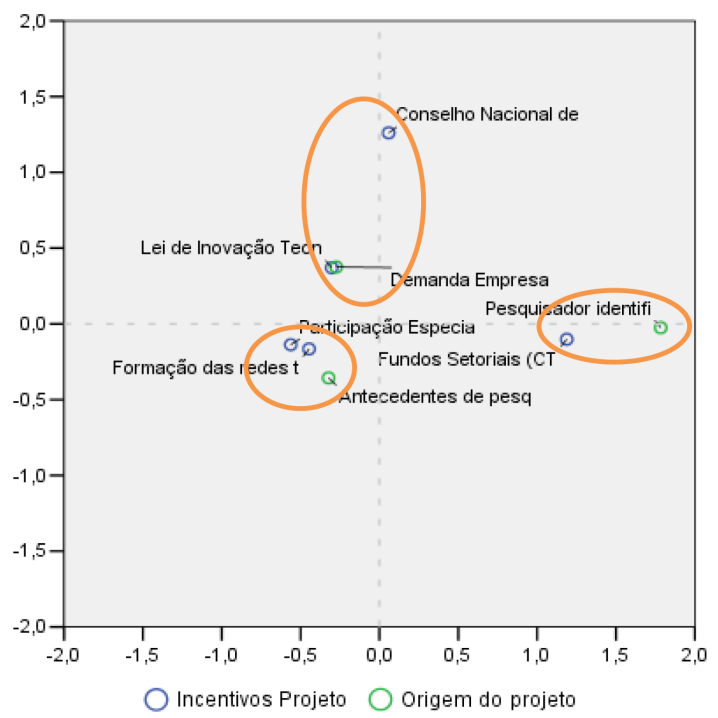

Figura 8. Principais incentivos para a realização do projeto. 
dos projetos. Os projetos demandados pela empresa destacam a Lei de Inovação Tecnológica e a política do Conselho Nacional de Política Energética como os principais incentivos para a realização dos projetos. No caso de o pesquisador identificar a oportunidade, o Fundo Setorial CTPETRO ressalta a condição de proposição de projetos por meio de editais de chamada pública da FINEP. A Formação das Redes Temáticas e a Participação Especial estão associadas com projetos com antecedentes de pesquisa, demonstrando a existência de pesquisadores qualificados e pesquisas em andamento com potencial aplicabilidade para a empresa.

\subsection{Impactos científicos e tecnológicos na UFRGS}

Neste aspecto, procurava-se identificar os principais impactos científicos e tecnológicos para a UFRGS, considerando o tipo de resultados obtidos com a realização dos projetos de interação.

Nota-se que os projetos realizados a partir da demanda da empresa têm resultados associados a artigos publicados e participação em eventos. Para projetos cuja oportunidade foi identificada pelo pesquisador, os principais resultados são bolsas de pesquisa, infraestrutura física e Pós-graduação (ver Figura 9). Conforme citado acima, para o desenvolvimento destes projetos, foram concedidas 74 bolsas de pesquisa distribuídas para alunos de graduação e pós-graduação. Além disso, houve investimentos em infraestrutura laboratorial, desde a aquisição de equipamentos de pequeno e grande porte, até a construção ou reforma de áreas específicas para estes laboratórios.

Para aqueles oriundos de antecedentes de pesquisa, é evidenciado o resultado em nível de formação de

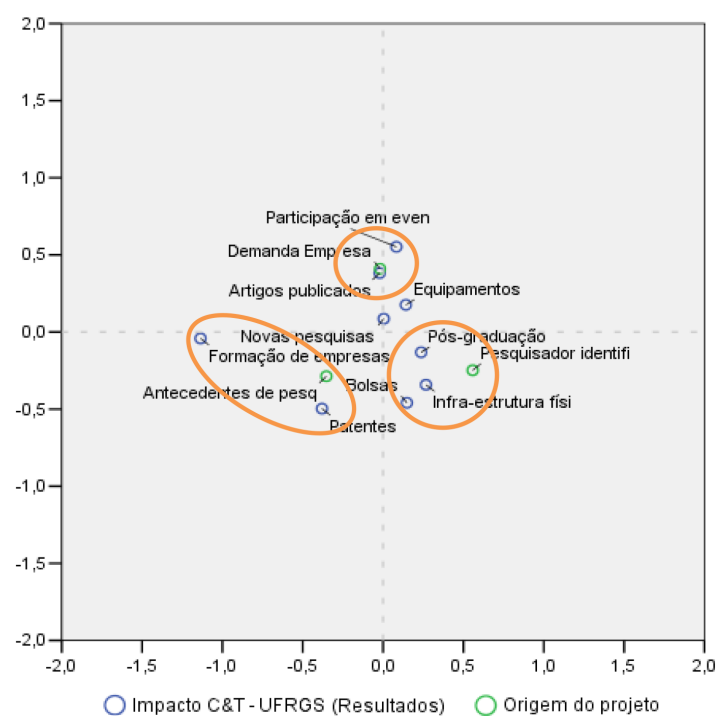

Figura 9. Impactos em C\&T para a UFRGS. empresas e patentes. É importante salientar que a formação de empresas está relacionada à identificação de oportunidades de incubação de empresas na própria UFRGS, a qual possui cinco incubadoras tecnológicas setoriais, sendo que estas empresas oriundas dos projetos encontram-se ainda em incubação: uma na área de engenharia (Incubadora Hestia) e outra na área de informática (Centro de Empreendimentos em Informática - CEI).

\subsection{Impactos científicos e tecnológicos na PETROBRAS}

Os impactos científicos e tecnológicos para a PETROBRAS a partir da realização dos projetos, considerando os tipos de resultados para a PETROBRAS também foram questionados. A Figura 10 apresenta os principais impactos em nível de resultados em função da origem dos projetos.

Estão associados aos projetos demandados pela empresa, resultados do tipo melhoria de produtos e atendimento à legislação. Quanto aos resultados advindos de projetos propostos pelo pesquisador, a associação é com resultados do tipo novos processos, atendimento à legislação e atendimento a padrões técnicos. Nos resultados dos projetos com antecedentes de pesquisa, evidenciam-se a geração de novos produtos, de novos fornecedores e a substituição de fornecedores externos. Sob este aspecto, é importante ressaltar que, para estes resultados de antecedentes, são processos de desenvolvimento e inovação decorrentes de um longo período de pesquisa, ressaltando as potencialidades existentes no ambiente acadêmico em termos de produção e aplicação do conhecimento.

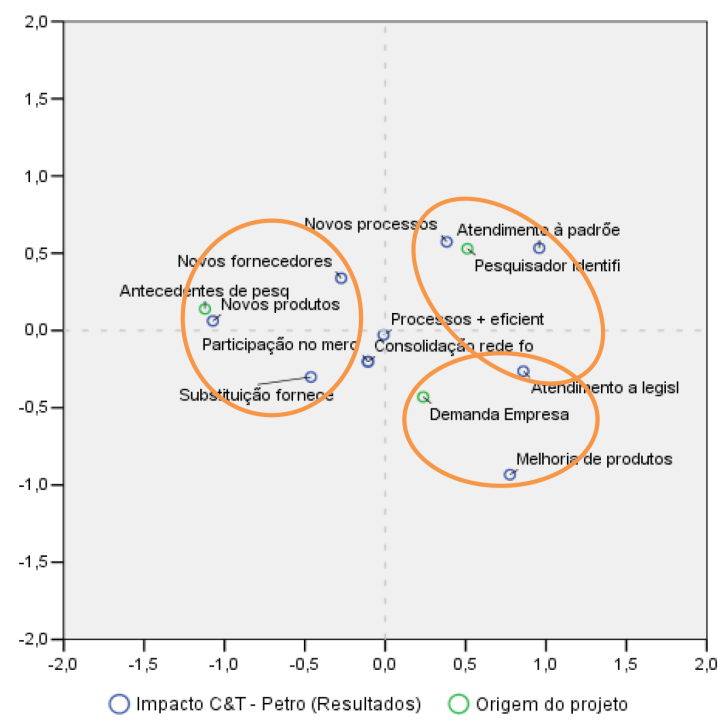

Figura 10. Impactos em C\&T para a Petrobrás. 


\subsection{Aspectos de maior impacto na aprovação/contratação do projeto}

Considerando alguns aspectos determinantes para a contratação da UFRGS para a realização dos projetos, foram questionados sobre quais teriam maior impacto para a aprovação e contratação definitiva pela PETROBRAS. Esta avaliação é fundamental para que seja ressaltado o potencial de interação pela qualidade acadêmica da universidade, porém na busca de melhorias em termos de procedimentos administrativos que visem agilizar os processos de formalização destas interações.

Os aspectos de maior impacto para os projetos sob a demanda da PETROBRAS foram: infraestrutura laboratorial, políticas de interação da universidade, tecnologias existentes, competência reconhecida e certificações. Para os projetos em que o pesquisador identificou a oportunidade, foram destacados aspectos como equipamentos de ponta, existência de projetos anteriores, tecnologias existentes e patentes existentes são mais recorrentes. Para projetos com antecedentes de pesquisa com aplicação na PETROBRAS, os aspectos demandados para a contração foram: existência de projetos anteriores, relacionamento existente, patentes existentes e competência reconhecida.

\subsection{Principais mecanismos de transferência de tecnologia utilizados para o repasse dos resultados}

O desenvolvimento tecnológico decorre do processo resultante da transferência de tecnologia para a criação de inovações no setor produtivo para a sociedade. Assim, os resultados de um projeto devem ser repassados à empresa por meio de determinados mecanismo de transferência da tecnologia desenvolvida, seja ela protegida ou não. As principais definições quanto aos mecanismos de transferência de tecnologia (TT) foram apresentados aos coordenadores, conforme visto na Figura 1.

A Figura 11 ilustra que o licenciamento e spin-off são os principais mecanismos de TT em função dos projetos sob a demanda da empresa. Pelos projetos que foram propostos pelo pesquisador, licenciamento e know-how são os principais mecanismos. Em projetos com antecedentes de pesquisa, empresas incubadas, empresas para parque tecnológico e patentes são mais impactantes. Neste caso, é possível compreender que há a intenção de substituição de fornecedores externos e criação de novos fornecedores, além do desenvolvimento de novos produtos, conforme citado acima na relação dos impactos científicos e tecnológicos produzidos na PETROBRAS.

\subsection{Intervenções realizadas no decorrer do projeto para a transferência dos resultados}

Foi questionado como são realizadas as intervenções no decorrer do projeto para a transferência e discussão dos resultados, sendo elas: reuniões; seminários e workshops; relatórios técnicos; protótipos; prestação de contas; e validação de experimentos.

No caso de intervenções de acordo com a origem dos projetos, aqueles demandados pela empresa destacam os protótipos e a validação de experimentos, sendo este último também associado aos projetos identificados pelos pesquisadores. Para aqueles cuja pesquisa era antecedente à parceria, a realização de reuniões é mais recorrente (ver Figura 12).

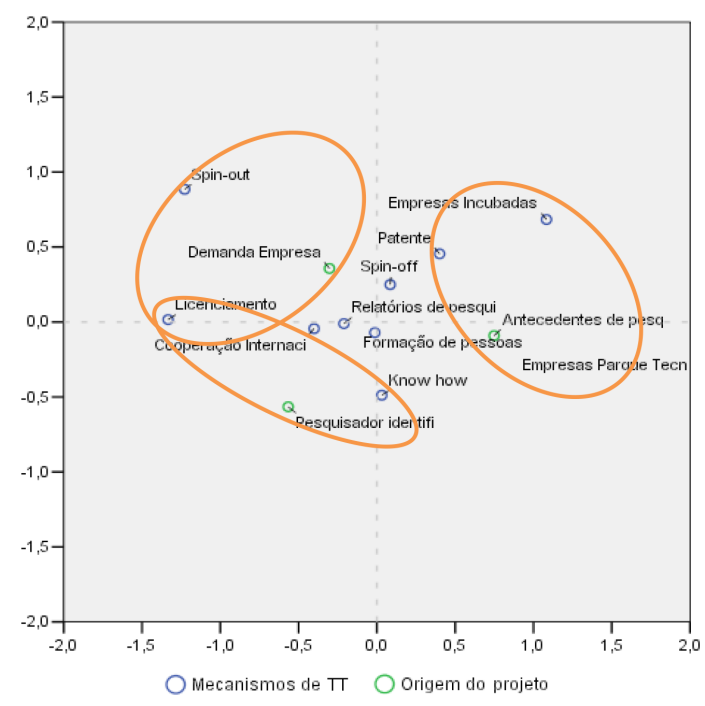

Figura 11. Mecanismos de TT utilizados para o repasse dos resultados desenvolvidos pelo projeto.

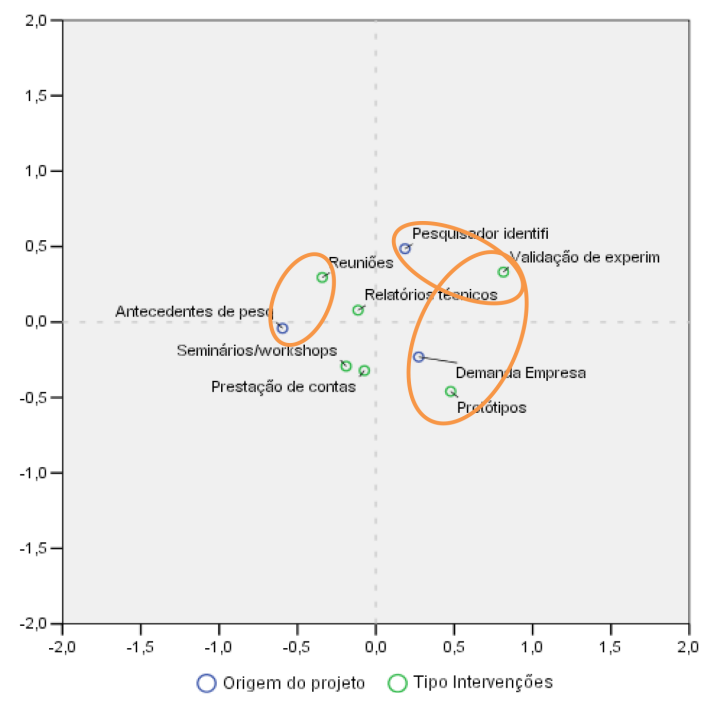

Figura 12. Tipos de intervenção em função da origem dos projetos. 


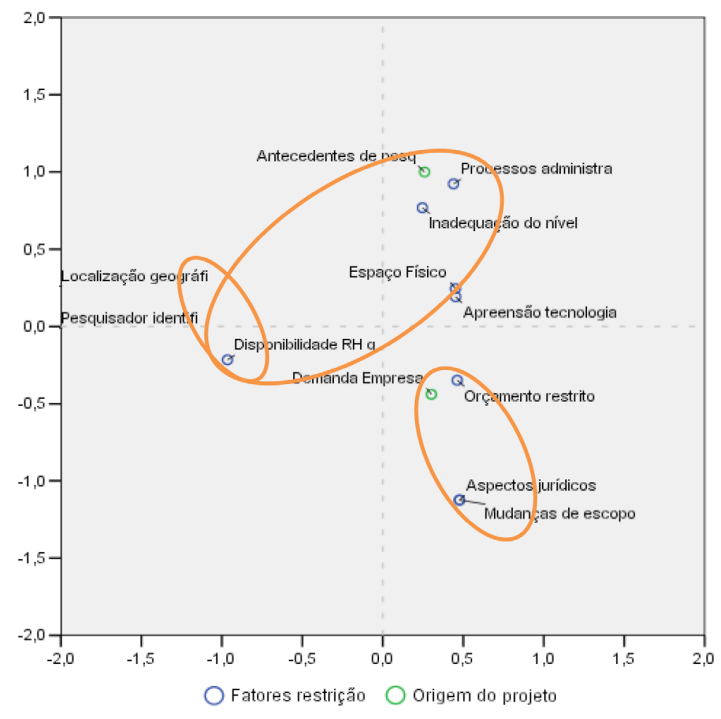

Figura 13. Fatores de restrição à execução adequada dos projetos em função da origem dos projetos.

\subsection{Principais fatores determinantes do sucesso do projeto}

Esta questão visava identificações de potencias fatores determinantes ao sucesso do projeto. No entanto, neste quesito, apenas a gestão do projeto foi destacada.

\subsection{Fatores de restrição para a adequada execução do projeto}

Esta questão visava à identificação de potencias fatores que restringissem a execução adequada do projeto. A Figura 13 apresenta os fatores de restrição à execução adequada dos projetos.

Os principais fatores de restrição demandados pela empresa destacaram os fatores de restrição: orçamento restrito, aspectos jurídicos e mudanças de escopo. Para projetos cujo pesquisador identificou a oportunidade, localização geográfica e disponibilidade de recursos humanos qualificados foram fatores restritivos. Para os projetos oriundos de antecedência de pesquisa, inadequação do nível de regras claras, espaço físico, disponibilidade de recursos humanos qualificados e processos administrativos não ágeis foram apontados como os principais fatores restritivos.

\section{Conclusão}

O objetivo deste trabalho foi analisar o impacto produzido por projetos de interação entre a UFRGS e a PETROBRAS, vinculados às políticas de investimento em $\mathrm{P} \& \mathrm{D}$ propostas pelo sistema de redes temáticas de pesquisa da empresa. Esta política considera a aplicação decorrente do Plano Nacional de Ciência e Tecnologia do Setor de Petróleo e Gás
Natural - CTPETRO e da Participação Especial, estipulados pela Lei Federal no 9.478/97 (Brasil, 1997).

O procedimento metodológico contemplou uma abordagem qualitativa e quantitativa, estruturado nas seguintes etapas: 1) Coleta de Dados: (i) pesquisa bibliográfica; (ii) Levantamento; 2) Análise multivariada de dados - Tabelas Cruzadas e Análise de Correspondência; e 3) Apresentação dos resultados.

A partir dos mapas perceptuais que apresentam as associações das questões com a variável origem dos projetos, considerando os valores de resíduos ajustados maiores do que 1, foi possível identificar as áreas de atuação da PETROBRAS; os principais objetivos científicos e tecnológicos dos projetos; os tipos de inovação envolvidos e os principais recursos demandados pela empresa para a realização do projeto. Outra informação relevante consiste na associação quanto aos resultados passíveis de proteção e os principais incentivos para a realização do projeto, identificando por meio disso as principais fontes de recursos investidos no projeto.

Os principais impactos científicos e tecnológicos resultados da realização do projeto tanto no âmbito da UFRGS como da PETROBRAS foram ressaltados, assim como o impacto dos resultados dos projetos em nível estratégico da empresa. Identificaram-se os benefícios resultantes tanto para a UFRGS como para a PETROBRAS, demonstrando a efetividade da interação. Também foi possível identificar os principais aspectos associados à aprovação e contratação do projeto por parte da empresa.

Por parte da UFRGS, foi importante identificar os principais mecanismos de transferência de tecnologia para o repasse dos resultados, os quais podem ser incentivados, bem como as maneiras de realizar intervenções no decorrer do projeto para a transferência dos resultados. Outro fator relevante para aprimorar o processo de interação é a compreensão dos principais fatores determinantes do sucesso do projeto e dos fatores restritivos à adequada execução do projeto. Cabe ressaltar também as negociações e o entendimento sobre as políticas de resultados protegíveis, uma vez que estes resultados são recorrentes e merecem atenção na tratativa dos projetos.

Os resultados do estudo podem fortalecer os projetos de interação entre os parceiros, em especial, aqueles dos pesquisadores das unidades acadêmicas envolvidas na pesquisa, que podem melhor direcionar suas pesquisas e projetos de acordo com as demandas da empresa. Também possibilitam uma análise quanto a aspectos institucionais que possam contribuir para a melhoria do processo de interação da UFRGS com a PETROBRAS. Neste sentido, a universidade tem realizado ações específicas e diferenciadas para a contratação dos projetos em parceria com a Petrobras, destacando os pontos estratégicos e os expressivos resultados para ambos na realização destas ações de interação. 


\section{Referências}

Agência Nacional do Petróleo, Gás Natural e Biocombustíveis -ANP. (2005a, 25 de novembro). Regulamento Técnico para o Credenciamento das Instituições de Pesquisa e Desenvolvimento. Regulamento ANP - no 6/2005 - Documento aprovado pela $R D n^{\circ} 372$, de 18 de novembro de 2005 e pela Resolução 34 de 24/11/2005 (seção 1). Brasília, DF: Diário Oficial da República Federativa do Brasil.

Agência Nacional do Petróleo, Gás Natural e Biocombustíveis -ANP. (2005b, 25 de novembro). Regulamento Técnico ANP $n^{\circ}$ 5/2005 (seção 1). Brasília, DF: Diário Oficial da República Federativa do Brasil. Recuperado em 29 de agosto de 2008, de http://sites.petrobras.com.br/ minisite/comunidade_cienciatecnologia/portugues/ docs/Regulamento.pdf

Agência Nacional do Petróleo, Gás Natural e Biocombustíveis -ANP. Recuperado em 16 de agosto de 2014, de http:// www.anp.gov.br

Associação Nacional de Entidades Promotoras de Empreendimentos Inovadores - ANPROTEC. Serviço Brasileiro de Apoio às Micro e Pequenas Empresas SEBRAE. (2002). Glossário dinâmico de termos na área de Tecnópolis, Parques Tecnológicos e Incubadoras de Empresas. Brasília.

Balestro, M. V. (2006). Capital Social, Aprendizado e Inovação: um estudo comparativo entre redes de inovação na indústria de petróleo e gás no Brasil e Canadá (Tese de doutorado). Universidade de Brasília, Brasília.

Benedetti, M. H., \& Torkomian, A. L. V. (2011). Uma análise da influência da cooperação UniversidadeEmpresa sobre a inovação tecnológica. Gestão \& Produção, 18(1), 145-158. http://dx.doi.org/10.1590/ S0104-530X2011000100011.

Bozeman, B. (2000). Technology transfer and public policy: a review of research and theory. Research Policy, 29(4-5), 627-655. http://dx.doi.org/10.1016/ S0048-7333(99)00093-1.

Brasil. (1997, 7 de agosto). Lei do Petróleo $N^{o}$ 9.478, de 06 de Agosto de 1997. Brasília, DF: Diário Oficial da República Federativa do Brasil. Recuperado em 24 de agosto de 2014, de http://www.planalto.gov.br/ccivil_03/ Leis/L9478.htm

Brasil. (1998, 4 de agosto). Decreto $n^{\circ} 2.705$, publicado em 03 de agosto de 1998 (seção 1, pp. 2). Brasília, DF: Diário Oficial da República Federativa do Brasil. Recuperado em 22 de setembro de 2008, de http://www. planalto.gov.br/ccivil_03/decreto/D2705.htm

Brasil. (2004, 3 de dezembro). Lei $n^{\circ}$ 10.973, de 2 de dezembro de 2004. Dispõe sobre incentivos à inovação e à pesquisa científica e tecnológica no ambiente produtivo e dá outras providências. Brasília, DF: Diário Oficial da República Federativa do Brasil. Recuperado em 23 de março de 2014, de http://www.planalto.gov.br/ ccivil_03/_Ato2004-2006/2004/Lei/L10.973.htmhttp://
www.planalto.gov.br/ccivil_03/_Ato2004-2006/2004/ Lei/L10.973.htm

Brasil. Ministério de Ciência e Tecnologia-MCT. (1999a, 13 de dezembro). Portaria MCT ${ }^{\circ} 552$, de 8 de dezembro de 1999 (seção I-E, pp. 41). Brasília, DF: Diário Oficial da República Federativa do Brasil. Recuperado em 16 de agosto de 2014, de http://www.mct.gov.br

Brasil. Ministério de Ciência e Tecnologia-MCT. (1999b). Plano Nacional de Ciência e Tecnologia do Setor Petróleo e Gás Natural: CTPETRO. Diretrizes Gerais. Versão 1. Recuperado em 16 de agosto de 2013, de http://www. mct.gov.br/upd_blob/0006/6942.pdf

Brasil. Ministério de Ciência e Tecnologia-MCT. (2005). Resolução Agência Nacional do Petróleo, Gás Naturale Biocombustiveis-ANP $n^{\circ} 33$, de 24 de novembro de 2005. Recuperado em 12 de setembro de 2015, de http://sites. petrobras.com.br/minisite/comunidade_cienciatecnologia/ portugues/docs/Resolucao-ANP.pdf

Canciglieri, O., Jr., Selhorst, A., Jr., \& Sant'Anna, A. M. O. (2015). Método de decisão dos processos de protoripagem rápida na concepção de novos produtos. Gestão \& Produção, 22(2), 315-355.

Closs, L. Q., \& Ferreira, G. C. (2012). Transferência de tecnologia universidade-empresa no contexto brasileiro: uma revisão de estudos científicos publicados entre os anos 2005 e 2009. Gestão \& Produção, 19(2), 419-432. http://dx.doi.org/10.1590/S0104-530X2012000200014.

Companhia de Petróleo Brasileiro S/A - PETROBRAS. Recuperado em 24 de abril de 2014, de http://www2. petrobras.com.br/minisite/comunidade_cienciatecnologia/ portugues/redes_tematicas.asp

Companhia de Petróleo Brasileiro S/A - PETROBRAS. Recuperado em 23 de janeiro de 2015, de http://www2. petrobras.com.br/portugues/ads/ads_petrobras.html

Confederação Nacional das Indústrias - CNI. Banco Mundial. (2008). Conhecimento e inovação para a competitividade. Brasília.

Coutinho, P. L. A. (2004). Estratégia tecnológica e gestão da Inovação: uma estrutura analítica voltada para os administradores de empresas (Tese de doutorado). Escola de Química, Universidade Federal do Rio de Janeiro, Rio de Janeiro.

Etzkowitz, H., \& Leydesdorff, L. (1998). The Triple Helix of University-Industry-Government Relations: Introduction. Industry and Higher Education, 4(1), 197-258.

Feldman, M., Feller, I., Bercovitz, J., \& Burton, R. (2002). Equity and the technology transfer strategies of American Research Universities. Management Science, 48(1), 105121. http://dx.doi.org/10.1287/mnsc.48.1.105.14276.

Freeman, C. (1987). Technology and economic performance: lesson from Japan. Londres: Frances Printer.

Freitas, A. G. (2002). Novo instrumento de politica cientifica e tecnológica no setor petrolífero nacional: a experiência do CTPETRO. Campinas: SPBC. Recuperado em 7 
de setembro de 2008, de http://www.comciencia.br/ reportagens/petroleo/pet22.shtml.

Furtado, A. T. (1996). A trajetória tecnológica da PETROBRAS na produção offshore. In R. Sbragia, J. Marcovitch \& E. Vasconcellos (Eds.), Anais do XIX Simpósio de Gestão da Inovação Tecnológica - SBRAGIA (pp. 813-832) São Paulo: USP/PGT/FIA/PACTO.

Hair, J., Anderson, R., Tatham, R., \& Black, W. (2005). Análise multivariada de dados. São Paulo: ARTMED.

Lemos, B., \& Joia, L. A. (2012). Relevant factors for tacit knowledge transfer within organizations: an exploratory study. Gestão \& Produção, 19(2), 233-246. http://dx.doi. org/10.1590/S0104-530X2012000200001.

Markard, J., \& Truffer, B. (2008). Technological innovation systems and the multi-level perspective: towards an integrated framework. Research Policy, 37(4), 596-615. http://dx.doi.org/10.1016/j.respol.2008.01.004.

Mowery, D., \& Sampat, B. (2005). Universities in national innovation systems. In J. Fargerberg, D. Mowery \& R. Nelson (Eds.), The Oxford Handbook of Innovation (pp. 209-239). Oxford: Oxford University Press.

Organização para Cooperação e Desenvolvimento Econômico - OCDE. (2004). Manual de Oslo: diretrizes para coleta e interpretação de dados sobre inovação (3 ed.). Rio de Janeiro: OCDE, Eurostat, FINEP.

Pereira, N. M. (2007). Fundos setoriais no Brasil: um pouco da história. Ciencia e Cultura, 59(4), 37-39.

Rossi, F. (2010). The governance of university-industry knowledge transfers. European Journal of Innovation Management, 13(2), 155-171. http://dx.doi. org/10.1108/14601061011040230.
Sant'Anna, A. M. O. (2015). Framework of decision in data modeling for quality improvement. The TQM Journal, 27(1), 135-149. http://dx.doi.org/10.1108/ TQM-06-2013-0066.

Segatto-Mendes, A. P. (1996). Análise do processo de cooperação tecnológica universidade-empresa: um estudo exploratório (Dissertação de mestrado). Departamento de Administração, Faculdade de Economia, Universidade de São Paulo, São Paulo.

Universidade Federal do Rio Grande do Sul - UFRGS. (2006). Portaria $n^{\circ} 2060$ de 31 julho de 2006. Regulamenta o $\S 1^{\circ}$ do art. 11 da Decisão $n^{\circ}$ 242/2005 - Conselho Universitário - CONSUN. Porto Alegre, RS. Recuperado em 27 de janeiro de 2013, de http://www.ufrgs.br/cepe/ legislacao/portaria-ufrgs-no-2060

Valle, M. G., Bonacelli, M. B. M., \& Salles, S. L. M., Fo. (2002). Os Fundos Setoriais e a Política Nacional de Ciência, Tecnologia e Inovação. In Anais XXII Simpósio de Gestão da Inovação Tecnológica. Salvador.

Vasconcelos, M. C. R. L., \& Ferreira, M. A. T. (2000). A contribuição da cooperação universidade/empresa para o conhecimento tecnológico da indústria. Perspectivas em Ciência da Informação, 5(2), 167-182.

Vedovello, C. (1997). Science parks and university-industry interaction: geographical proximity between the agents as a driving force. Technovation, 17(9), 491-502. http:// dx.doi.org/10.1016/S0166-4972(97)00027-8.

Zamith, R., \& Santos, E. M. O. (1998). Diamante petroleiro brasileiro em perspectiva. In Anais do 3 Congresso Brasileiro de Planejamento Energético (pp. 105-110). São Paulo: SEESP/SBPE/USP/UNICAMP/COPEE-UFRJ. 